\title{
Dietary n-3 polyunsaturated fatty acids, fish consumption, and endometrial cancer risk: a meta-analysis of epidemiological studies
}

\author{
Rui Hou ${ }^{1}$, Shen-Shen Yao', Jia Liu' ${ }^{1}$, Lian-Lian Wang ${ }^{1}$, Lang $\mathbf{W u}^{2}$ and Luo Jiang ${ }^{3}$ \\ ${ }^{1}$ Department of Obstetrics and Gynecology, Shengjing Hospital Affiliated to China Medical University, Shenyang, P.R. China \\ ${ }^{2}$ Division of Epidemiology, Department of Medicine, Vanderbilt Epidemiology Center, Vanderbilt-Ingram Cancer Center, \\ Vanderbilt University Medical Center, Nashville, Tennessee, USA \\ ${ }^{3}$ Department of Ultrasound, Shengjing Hospital Affiliated to China Medical University, Shenyang, P.R. China \\ Correspondence to: Luo Jiang, email: jiangl@sj-hospital.org
}

Keywords: $n-3$ fatty acids, fish, epidemiology, endometrial cancer

Received: March 27, $2017 \quad$ Accepted: May 21, $2017 \quad$ Published: May 30, 2017

Copyright: Hou et al. This is an open-access article distributed under the terms of the Creative Commons Attribution License 3.0 (CC BY 3.0), which permits unrestricted use, distribution, and reproduction in any medium, provided the original author and source are credited.

\section{ABSTRACT}

The relationship between intake of fish and n-3 fatty acids and endometrial cancer risk has not been consistent across epidemiological studies. We quantitatively assessed the aforementioned association through a systematic review and metaanalysis. PubMed and Embase were searched through March 2017 for eligible epidemiological studies. Fixed or random-effects models were used to pool relative risks (RRs) and 95\% confidence intervals (CIs). The dose-response relationship was also evaluated. Based on the literature search, five prospective studies and 11 case-control studies were identified. All 16 studies were categorized as high-quality studies. After pooling available risk estimates, no significant association was detected between overall fish intake and endometrial cancer risk. In subgroup analyses, every one additional serving/week of fish intake was significantly associated with inversed endometrial cancer risk in studies adjusted for smoking (RR (95\% CI): 0.95 $(0.91-1.00)$ ), or studies performed in Europe (RR (95\% CI): 0.90 (0.84-0.97)), but not in other tested subgroups. In studies conducted in Asia, there was significant positive association (RR (95\% CI): 1.15 (1.10-1.21)). Regarding n-3 PUFA intake, marginally inverse associations of high EPA or DHA intake were detected (EPA: RR $(95 \%$ CI $)=0.79(0.61-1.04)$; DHA: RR $(95 \%$ CI $)=0.85(0.64-1.11))$. Dose-response analyses suggested a significant nonlinear relationship between DHA intake and endometrial cancer risk ( $p: 0.04$ ). Overall, this meta-analysis suggests that intake of n-3 PUFA may be inversely associated with endometrial cancer risk at some level of evidence, although the exact relationship, especially for fish intake, needs further characterization. Further well-designed studies are warranted.

\section{INTRODUCTION}

As one of the most common female pelvic malignancies, endometrial cancer represents the sixth leading cause of cancer incidence in women worldwide in 2012 [1]. In US alone, it is expected that there will be approximately 61,380 new endometrial cancer cases and 10,920 estimated deaths in 2017 [2]. It is critical to better understand the etiology of this cancer, and identify appropriate interventions to decrease its public health burden. Fish, an important part of diets worldwide, has been shown to be relevant to multiple human diseases, including several types of cancer [3-12]. Research suggests that specific types of fish contain high levels of $n-3$ polyunsaturated fatty acids (PUFAs) (e.g., eicosapentaenoic acid (EPA) and docosahexanoic acid (DHA)), which can potentially exert anti-inflammatory and anti-carcinogenic effects [13]. Despite this knowledge, however, the 
association between intake of fish and n-3 PUFA with endometrial cancer risk has not been consistently reported across epidemiological studies. For example, in several studies, the highest category of fish or n-3 PUFA intake was significantly associated with a decreased endometrial cancer risk [14-17]. Fernandez et al. reported a doseresponse relationship between fish consumption and decreased endometrial cancer risk [13]. However, such a significant association was not detected in other studies $[16,18-23]$. In two other studies conducted in Asia, high fish consumption was detected to confer an increased risk of developing endometrial cancer [24, 25]. Different studies may vary regarding study designs, subject eligibilities, statistical analyses and sample sizes. It is thus critical to synthesize available evidence to better understand whether fish/n-3 PUFA may represent one possible strategy for endometrial cancer prevention.

Bandera et al. conducted a meta-analysis summarizing studies up to 2006 and identified no association between overall fish intake and endometrial cancer risk [26]. In this study, however, authors did not synthesize evidence for the associations of n-3 PUFA including EPA and DHA. Besides, since the conduction of this meta-analysis, multiple additional studies evaluating association of fish consumption have been published $[14,16,18-20,24,27,28]$. To better characterize the relationship between intakes of fish/n-3 PUFA and endometrial cancer risk, we thus conducted a systematic review and meta-analysis of all available epidemiological studies up to March 2017. We also performed doseresponse analyses to carefully assess potential doseresponse relationship of the research question of interest.

\section{RESULTS}

\section{Literature search and study characteristics}

The detailed literature search and article screening processes are shown in Figure 1. In brief, 900 articles were identified through the literature search. After screening the titles and abstracts using the predefined criteria, 861 articles were excluded, leaving 39 articles to be fully assessed. Among these articles, 26 were further excluded because they did not meet the eligibility criteria $(n=4)$, did not report usable data of risk estimates $(n=18)$, or contained duplicate subjects with other larger studies $(n=4)$. We further identified 3 additional eligible studies by screening the reference lists of the included studies and relevant review and meta-analysis publications. Overall, a total of 16 studies met our inclusion criteria and were included in the meta-analysis [13-22, 24, 25, 28-31]. The detailed characteristics of the included studies are shown in Supplementary Table 1. Briefly, four prospective cohort studies, one case-cohort study, and 11 case-control studies (including eight population-based case-control studies and three hospital-based case-control studies) were included. The prospective studies have relatively long follow-up periods (median 9-18 years; mean 6.5-9.1 years). The highest category of fish, DHA and EPA consumption ranged from $>1-2$ servings/week to $>15.4$ servings/week, 143 to $227 \mathrm{mg} / \mathrm{d}$, and 74.7 to $127 \mathrm{mg} / \mathrm{d}$, respectively. Nine were conducted in North America, four were conducted in Asia, and three were conducted in Europe. The quality ratings for these studies are shown in Tables 1 and 2. Overall, all 16 studies were classified as high-quality studies.

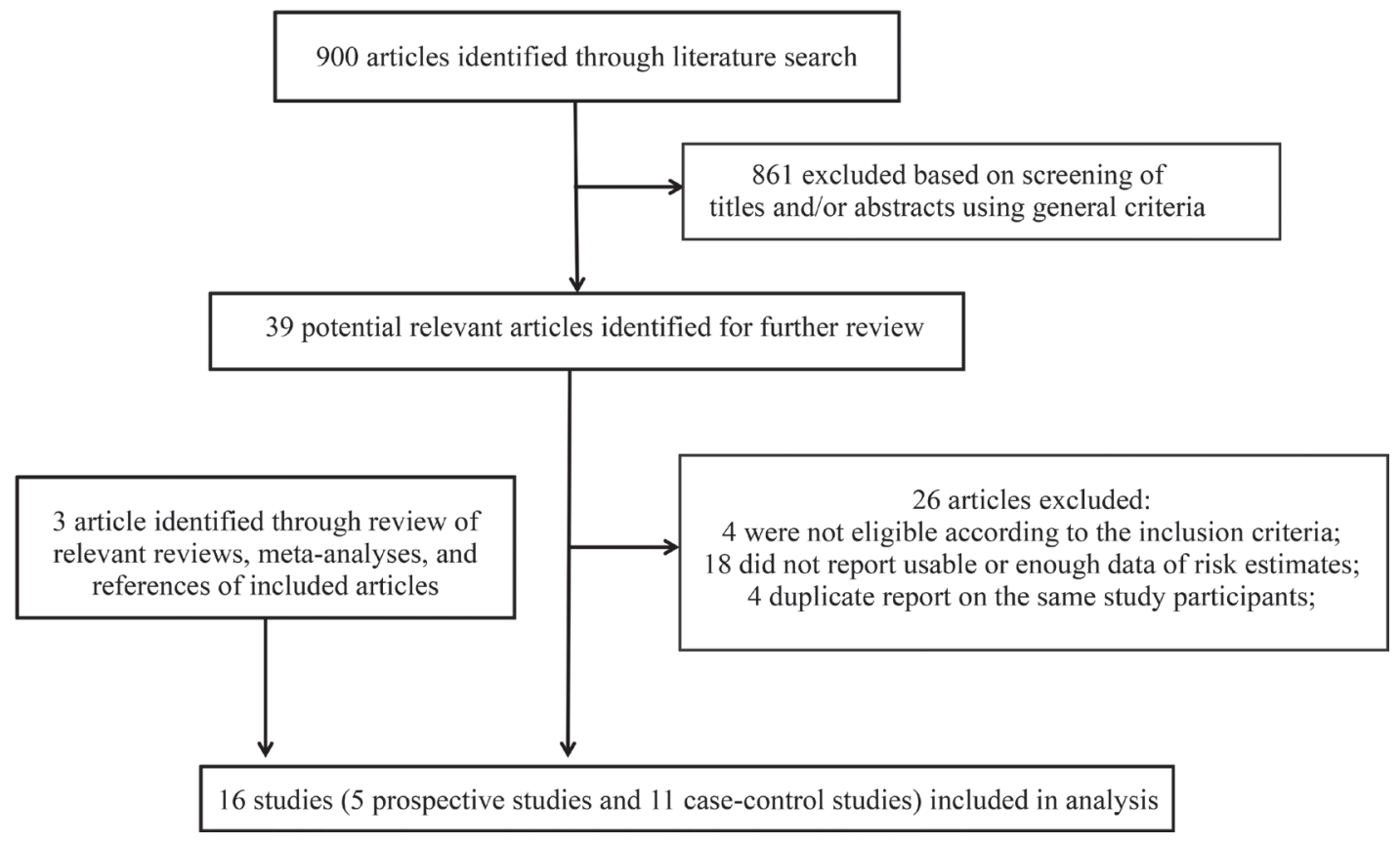

Figure 1: Flow chart for selection of eligible studies. 
Table 1: Quality assessment of included prospective studies using the Newcastle-Ottawa Quality assessment scale*

\begin{tabular}{|c|c|c|c|c|c|c|c|c|c|}
\hline Study & $\begin{array}{c}\text { Exposed } \\
\text { cohort } \\
\text { represents } \\
\text { average in } \\
\text { community }\end{array}$ & $\begin{array}{c}\text { Selection } \\
\text { of the non- } \\
\text { exposed } \\
\text { cohort } \\
\text { from same } \\
\text { community }\end{array}$ & $\begin{array}{l}\text { Ascertain } \\
\text { exposure } \\
\text { through } \\
\text { records or } \\
\text { structured } \\
\text { interviews }\end{array}$ & $\begin{array}{c}\text { Demonstrate } \\
\text { that outcome } \\
\text { not present at } \\
\text { study start }\end{array}$ & $\begin{array}{c}\text { Exposed and } \\
\text { non-exposed } \\
\text { matched and/ } \\
\text { or adjusted } \\
\text { by factors }\end{array}$ & $\begin{array}{c}\text { Ascertain } \\
\text { outcome via } \\
\text { independent } \\
\text { blind } \\
\text { assessment or } \\
\text { record linkage }\end{array}$ & $\begin{array}{l}\text { Follow-up } \\
\text { long enough } \\
\text { for outcome } \\
\text { to occur }\end{array}$ & $\begin{array}{c}\text { Loss to } \\
\text { follow- } \\
\text { up } \\
<20 \%\end{array}$ & $\begin{array}{c}\text { Overall } \\
\text { Score }\end{array}$ \\
\hline Brasky, 2014 & 1 & 1 & 0 & 1 & 2 & 1 & 1 & 1 & 8 \\
\hline Brasky, 2016 & 1 & 1 & 0 & 1 & 2 & 1 & 1 & 1 & 8 \\
\hline Daniel, 2011 & 1 & 1 & 0 & 1 & 2 & 1 & 1 & 1 & 8 \\
\hline $\begin{array}{l}\text { van } \\
\text { Lonkhuijzen, } \\
2011\end{array}$ & 1 & 1 & 0 & 1 & 2 & 1 & 1 & 1 & 8 \\
\hline Brasky, 2015 & 1 & 1 & 0 & 1 & 2 & 1 & 1 & 1 & 8 \\
\hline
\end{tabular}

*A study could be awarded a maximum of one star for each item except for the item Control for important factor or additional factor. The definition/ explanation of each column of the Newcastle-Ottawa Scale is available from (http://www.ohri.ca/programs/clinical_epidemiology/oxford.asp.). 1 means study adequately fulfilled a quality criterion ( 2 for exposed and non-exposed fully matched or adjusted by factors), 0 means it did not. Quality scale does not imply that items are of equal relevant importance

Table 2: Quality assessment of included case-control studies using the Newcastle-Ottawa Quality assessment scale*

\begin{tabular}{|c|c|c|c|c|c|c|c|c|c|}
\hline Study & $\begin{array}{c}\text { Case } \\
\text { defined with } \\
\text { independent } \\
\text { validation }\end{array}$ & $\begin{array}{c}\text { Representativeness } \\
\text { of the cases }\end{array}$ & $\begin{array}{c}\text { Selection } \\
\text { of controls } \\
\text { from } \\
\text { community }\end{array}$ & $\begin{array}{c}\text { Statement } \\
\text { that } \\
\text { controls } \\
\text { have no } \\
\text { history of } \\
\text { outcome }\end{array}$ & $\begin{array}{c}\text { Cases and } \\
\text { controls } \\
\text { matched } \\
\text { and } / \text { or } \\
\text { adjusted by } \\
\text { factors }\end{array}$ & $\begin{array}{c}\text { Ascertain } \\
\text { exposure } \\
\text { by blinded } \\
\text { structured } \\
\text { interview }\end{array}$ & $\begin{array}{c}\text { Same } \\
\text { method of } \\
\text { ascertainment } \\
\text { for cases and } \\
\text { controls }\end{array}$ & $\begin{array}{l}\text { Same } \\
\text { response } \\
\text { rate for } \\
\text { both } \\
\text { groups }\end{array}$ & $\begin{array}{c}\text { Overall } \\
\text { Score }\end{array}$ \\
\hline Arem, 2013 & 0 & 1 & 1 & 1 & 2 & 0 & 1 & 1 & 7 \\
\hline $\begin{array}{l}\text { Filomeno, } \\
2015\end{array}$ & 1 & 1 & 0 & 1 & 2 & 1 & 1 & 1 & 8 \\
\hline Hirose, 1996 & 1 & 1 & 0 & 1 & 2 & 0 & 1 & 1 & 7 \\
\hline $\begin{array}{l}\text { Takayama, } \\
2013\end{array}$ & 1 & 1 & 1 & 1 & 2 & 0 & 1 & 1 & 8 \\
\hline Terry, 2002 & 1 & 1 & 1 & 0 & 2 & 0 & 1 & 1 & 7 \\
\hline Xu, 2006 & 1 & 1 & 1 & 0 & 2 & 1 & 1 & 1 & 8 \\
\hline McCann, 2000 & 1 & 1 & 1 & 0 & 2 & 1 & 1 & 1 & 8 \\
\hline Jain, 2000 & 1 & 1 & 1 & 0 & 2 & 1 & 1 & 0 & 7 \\
\hline Shu, 1993 & 1 & 1 & 1 & 0 & 1 & 1 & 1 & 1 & 7 \\
\hline $\begin{array}{l}\text { Goodman, } \\
1997\end{array}$ & 1 & 1 & 1 & 0 & 2 & 1 & 1 & 1 & 8 \\
\hline $\begin{array}{l}\text { Fernandez, } \\
1999\end{array}$ & 1 & 1 & 0 & 1 & 2 & 1 & 1 & 1 & 8 \\
\hline
\end{tabular}

*A study could be awarded a maximum of one star for each item except for the item Control for important factor or additional factor. The definition/ explanation of each column of the Newcastle-Ottawa Scale is available from (http://www.ohri.ca/programs/clinical_epidemiology/oxford.asp.). 1 means study adequately fulfilled a quality criterion ( 2 for case-control fully matched and adjusted), 0 means it did not. Quality scale does not imply that items are of equal relevant importance

\section{Fish consumption and endometrial cancer risk}

Twelve studies reported the association of fish consumption with endometrial cancer risk comparing the highest category with the lowest category [14-16, 18$22,24,25,28,31]$. After pooling the results of these studies, we did not detect a significant association between the highest $v s$. lowest category of fish consumption and endometrial cancer risk $(\mathrm{RR}=1.04,95 \% \mathrm{CI}=0.84-1.30)$, with relatively high heterogeneity $\left(I^{2}=80.4 \%\right.$; Table 3 , Figure 2). No apparent publication bias was identified by
Egger's test ( $p$ for bias: 0.850) or Begg's test ( $p$ for bias: 0.631 ). According to the subgroup analyses (Table 3), the null association persisted in strata according to study design, location, type of controls, number of cases, publication year, and adjustments of energy intake, reproductive factors, and smoking (Table 3 ).

Data from eight studies were used to evaluate a non-linear dose-response relationship between fish intake and risk of endometrial cancer risk $[13,15,16$, $18,22,25,28,31]$. Assuming a non-linear relationship, the dose-response analysis suggested a non-significant 
relationship ( $p: 0.81)$. The test for nonlinearity suggested that a linear relationship might be more appropriate ( $p$ for nonlinearity: 0.77). Assuming a linear relationship, we also incorporated two additional studies with available data [29, 30], and detected that the combined RR per one additional serving/week of fish intake was 1.00 (95\% CI 0.94-1.07), with considerable heterogeneity $(P$ for heterogeneity $<0.001)$ (Table 4$)$. Subgroup analyses suggested that for every one additional serving/week of fish intake, although the null association existed in the majority of tested strata, a significant inverse association was detected in studies conducted in Europe (RR: 0.90 (0.84-0.97)) (Table 4), and a significant positive association was detected in studies conducted in Asia (RR: 1.15 (1.10-1.21)) (Table 4). Furthermore, studies adjusting for smoking suggested a significant inverse association (RR: $0.95(0.91-1.00)$ ), while studies without an adjustment of smoking revealed a significant positive association (RR: 1.14 (1.09-1.19)) (Table 4).

\section{Intake of EPA/DHA and endometrial cancer risk}

After pooling relevant association estimates from four studies [16-18, 24], a nonsignificant inverse association between the highest category of EPA intake and endometrial cancer risk was detected $(\mathrm{RR}=0.79$, $95 \% \mathrm{CI}=0.61-1.04 ; I^{2}=57.7 \%$ ). Based on dose-response analyses of two studies $[17,24]$, there was neither a nonlinear relationship ( $p: 0.24)$, nor a significant linear relationship ( $p$ : 0.66$)$ of EPA intake.
Based on four studies [16-18, 24] reporting association of DHA, there was a nonsignificant inverse association between the highest category of DHA intake and endometrial cancer risk $(\mathrm{RR}=0.85,95 \% \mathrm{CI}=0.64$ $\left.1.11 ; I^{2}=59.6 \%\right)$. The dose-response analysis suggested a significant non-linear relationship between DHA intake and endometrial cancer risk ( $p$ : $0.04 ; p$ for heterogeneity: 0.39 ; Figure 3 ). The test for nonlinearity suggested that such a nonlinear relationship might be more appropriate than a linear relationship ( $p$ for nonlinearity: 0.04).

\section{DISCUSSION}

We performed a comprehensive systematic review and meta-analysis of epidemiological studies to assess the association between intake of fish/n-3 PUFA and endometrial cancer risk. After summarizing all available evidence, no significant association was detected for intake of overall fish, which is consistent with findings from an earlier meta-analysis [26]. However, a significant inverse association between every one additional serving/week of fish intake and endometrial cancer risk was detected in studies conducted in Europe, and studies adjusted for smoking. With regards to n-3 PUFA, we detected a significant non-linear relationship between DHA intake and risk of endometrial cancer, with a decreased risk being detected for an intake of DHA no more than $\sim 175 \mathrm{mg} / \mathrm{d}$. A high EPA intake was also suggestively associated with decreased endometrial cancer risk. Further studies would be needed to better characterize the relationship of interest.

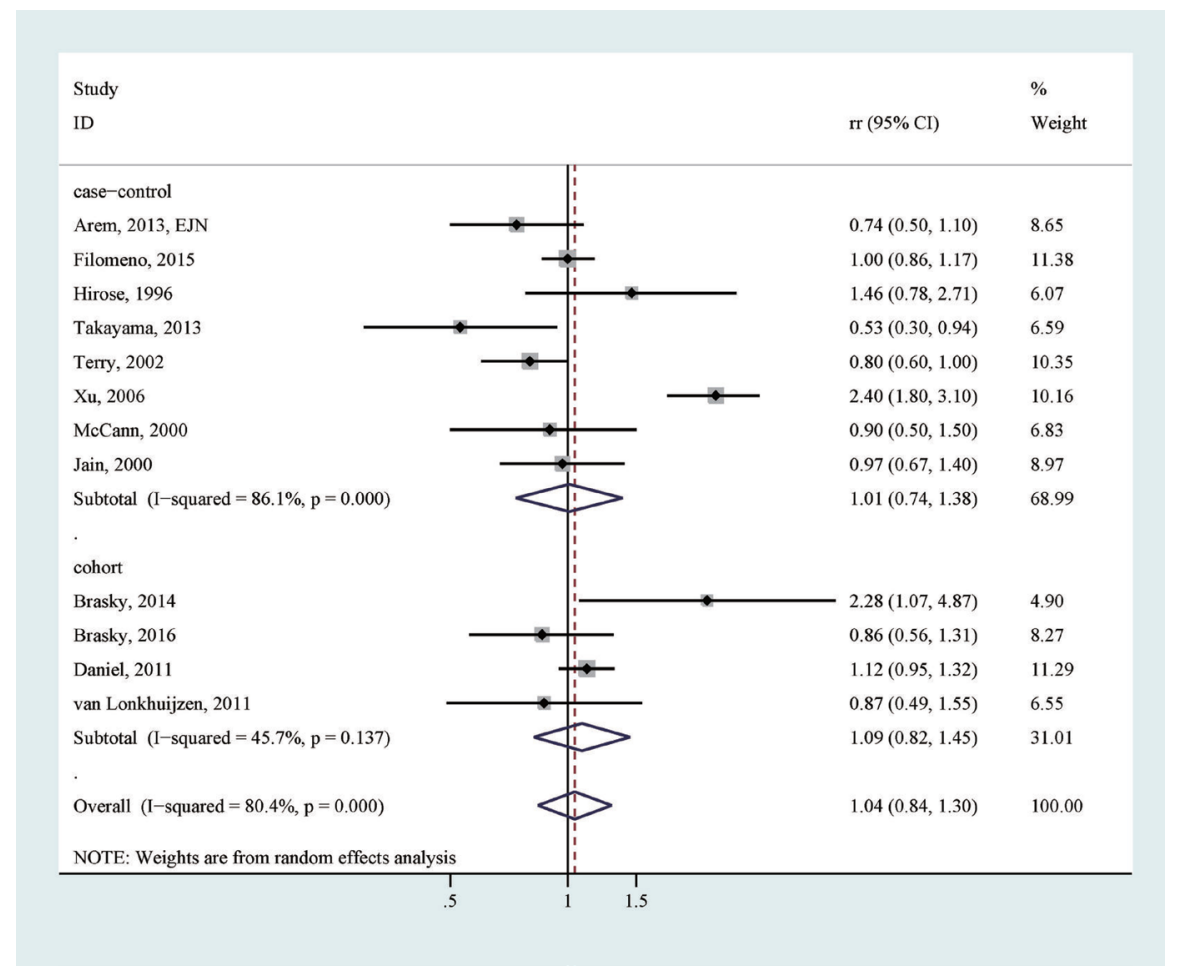

Figure 2: The association between the highest vs. lowest category of fish consumption and endometrial cancer risk. 
Table 3: Summary risk estimates of the association between fish consumption and endometrial cancer risk (the highest category versus the lowest category)

\begin{tabular}{|c|c|c|c|c|}
\hline & No. of reports & $\operatorname{RR}(95 \% \mathrm{CI})$ & $I^{2}$ & $P$ for heterogeneity \\
\hline Overall & 12 & $1.04(0.84-1.30)$ & $80.4 \%$ & $<0.001$ \\
\hline \multicolumn{5}{|l|}{ Subgroup analysis } \\
\hline \multicolumn{5}{|l|}{ Study design } \\
\hline Prospective & 4 & $1.09(0.82-1.45)$ & $45.7 \%$ & 0.137 \\
\hline Case-control & 8 & $1.01(0.74-1.38)$ & $86.1 \%$ & $<0.001$ \\
\hline \multicolumn{5}{|l|}{ Location } \\
\hline North America & 7 & $0.99(0.82-1.19)$ & $35.3 \%$ & 0.158 \\
\hline Europe & 2 & $0.92(0.74-1.13)$ & $53.5 \%$ & 0.142 \\
\hline Asia & 3 & $1.26(0.50-3.17)$ & $91.0 \%$ & $<0.001$ \\
\hline \multicolumn{5}{|l|}{ Type of controls } \\
\hline Population-based & 6 & $0.95(0.60-1.52)$ & $89.7 \%$ & $<0.001$ \\
\hline Hospital-based & 2 & $1.07(0.81-1.41)$ & $25.2 \%$ & 0.248 \\
\hline \multicolumn{5}{|l|}{ Number of cases } \\
\hline$<500$ & 6 & $0.98(0.69-1.39)$ & $55.8 \%$ & 0.046 \\
\hline$\geq 500$ & 6 & $1.09(0.81-1.45)$ & $88.5 \%$ & $<0.001$ \\
\hline \multicolumn{5}{|c|}{ Study publication time } \\
\hline Earlier than 2010 & 5 & $1.20(0.72-1.99)$ & $89.3 \%$ & $<0.001$ \\
\hline $2010-$ & 7 & $0.95(0.78-1.15)$ & $57.3 \%$ & 0.029 \\
\hline \multicolumn{5}{|c|}{ Estimate adjusted for energy intake } \\
\hline Yes & 8 & $1.14(0.88-1.48)$ & $83.6 \%$ & $<0.001$ \\
\hline No & 4 & $0.84(0.61-1.17)$ & $47.2 \%$ & 0.128 \\
\hline \multicolumn{5}{|c|}{ Estimate adjusted for reproductive factors } \\
\hline Yes & 9 & $1.14(0.85-1.54)$ & $81.8 \%$ & $<0.001$ \\
\hline No & 3 & $0.84(0.59-1.21)$ & $78.7 \%$ & 0.009 \\
\hline \multicolumn{5}{|c|}{ Estimate adjusted for smoking } \\
\hline Yes & 9 & $0.98(0.86-1.13)$ & $41.2 \%$ & 0.092 \\
\hline No & 3 & $1.06(0.39-2.85)$ & $92.7 \%$ & $<0.001$ \\
\hline \multicolumn{5}{|c|}{ Estimate adjusted for energy intake, reproductive factors and smoking } \\
\hline Yes & 5 & $0.97(0.78-1.20)$ & $44.0 \%$ & 0.128 \\
\hline No & 7 & $1.06(0.74-1.53)$ & $86.8 \%$ & $<0.001$ \\
\hline
\end{tabular}

The identified inverse association between DHA intake and endometrial cancer risk is plausible from biological perspectives. DHA is associated with reduced inflammation [32-35], which is known to play an important role in endometrial cancer etiology[36-39]. The antiinflammatory properties of DHA may be due not only to the inhibition of nuclear factor kappa B, but also the downstream modulation of the cyclooxygenase-2 pathway [40]. It has been suggested that the inhibition of the cyclooxygenase- 2 blockade may also be associated with reduced estrogen synthesis [41], which is known to be able to drive endometrial proliferation [42, 43]. Furthermore, research suggests that n-3 PUFA may decrease the production of superoxide and free radicals [44], and may influence insulin sensitivity and cell membrane fluidity $[45,46]$, all of which may protect from carcinogenesis. This is consistent with our finding of an inverse association of high EPA intake, albeit the statistical significance is not reached.

Our finding of a null association of overall fish intake may be explained by several reasons. One possible explanation is that only fatty fish is associated with reduced endometrial cancer risk due to its enrichment of n-3 PUFA, and thus many studies assessing the overall fish intake could not identify the association due to the mixture of fish types evaluated. In a nation-wide case-control study in Sweden, it was indeed that only consumption of fatty 
Table 4: Summary risk estimates of the association between fish consumption and endometrial cancer risk (every one additional serving/week of fish intake)

\begin{tabular}{|c|c|c|c|c|}
\hline & No. of reports & RR $(95 \%$ CI $)$ & $I^{2}$ & $P$ for heterogeneity \\
\hline Overall & 10 & $1.00(0.94-1.07)$ & $81.7 \%$ & $<0.001$ \\
\hline \multicolumn{5}{|l|}{ Subgroup analysis } \\
\hline \multicolumn{5}{|l|}{ Study design } \\
\hline Prospective & 2 & $1.00(0.97-1.02)$ & $0 \%$ & 0.778 \\
\hline Case-control & 8 & $1.01(0.92-1.10)$ & $83.9 \%$ & $<0.001$ \\
\hline \multicolumn{5}{|l|}{ Location } \\
\hline North America & 6 & $1.00(0.95-1.04)$ & $32.6 \%$ & 0.191 \\
\hline Europe & 2 & $0.90(0.84-0.97)$ & $0 \%$ & 0.941 \\
\hline Asia & 2 & $1.15(1.10-1.21)$ & $0 \%$ & 0.531 \\
\hline \multicolumn{5}{|l|}{ Type of controls } \\
\hline Population-based & 9 & $1.02(0.93-1.12)$ & $83.2 \%$ & $<0.001$ \\
\hline Hospital-based & 1 & $0.90(0.80-1.00)$ & - & - \\
\hline \multicolumn{5}{|l|}{ Number of cases } \\
\hline$<500$ & 5 & $1.03(0.97-1.10)$ & $42.5 \%$ & 0.138 \\
\hline$\geq 500$ & 5 & $0.97(0.86-1.10)$ & $90.1 \%$ & $<0.001$ \\
\hline \multicolumn{5}{|c|}{ Study publication time } \\
\hline Earlier than 2010 & 7 & $1.02(0.93-1.12)$ & $82.7 \%$ & $<0.001$ \\
\hline 2010 & 3 & $0.98(0.94-1.03)$ & $19.7 \%$ & 0.288 \\
\hline \multicolumn{5}{|c|}{ Estimate adjusted for energy intake } \\
\hline Yes & 5 & $1.01(0.93-1.11)$ & $88.2 \%$ & $<0.001$ \\
\hline No & 5 & $0.99(0.89-1.10)$ & $72.5 \%$ & 0.006 \\
\hline \multicolumn{5}{|c|}{ Estimate adjusted for reproductive factors } \\
\hline Yes & 6 & $1.01(0.93-1.09)$ & $85.4 \%$ & $<0.001$ \\
\hline No & 4 & $1.00(0.89-1.12)$ & $79.1 \%$ & 0.002 \\
\hline \multicolumn{5}{|c|}{ Estimate adjusted for smoking } \\
\hline Yes & 6 & $0.95(0.91-1.00)$ & $41.1 \%$ & 0.131 \\
\hline No & 4 & $1.14(1.09-1.19)$ & $0 \%$ & 0.399 \\
\hline \multicolumn{5}{|c|}{ Estimate adjusted for energy intake, reproductive factors and smoking } \\
\hline Yes & 3 & $0.98(0.95-1.02)$ & $19.5 \%$ & 0.289 \\
\hline No & 7 & $1.02(0.92-1.12)$ & $82.1 \%$ & $<0.001$ \\
\hline
\end{tabular}

fish, but not other types of fish, was significantly associated with reduced endometrial cancer risk. Another reason is that different methods of cooking/preparing fish may induce the heterogeneities across studies. For example, in China, people often tend to cook fish using deep frying methods, which could lead to formation of mutagens and carcinogens, such as heterocyclic amines [16, 29]. Many Chinese population may also consume salted, dried fish which may contains N-nitrosamines. These may explain why studies in Asia (China) detected a positive association between fish intake and endometrial cancer development $[16,25,29]$, in contract to studies in other regions such as Europe, which suggested an inverse association. Careful collection and analyses of fish cooking methods, along with fish types may be able to provide a better clue for the heterogeneity of the identified associations in different regions. Furthermore, it is possible that residual confounding may be an issue for some of the included studies. For example, studies adjusting for smoking, a known risk factor for endometrial cancer risk, suggested a significant inverse association for every one additional serving/week of fish intake while those without smoking adjustment suggested the opposite direction.

Our study has several strengths. To our knowledge, this is the most comprehensive meta-analysis evaluating the association between fish consumption and endometrial cancer risk. The synthetization of evidence focusing on $n-3$ PUFA with endometrial cancer risk, based on our knowledge, 
is for the first time. In addition to conducting multiple subgroup analyses to further evaluate the association, we performed dose-response analyses to further clarify the relationship. Findings of our analyses suggested a potential beneficial role of DHA/EPA in reducing endometrial cancer development, which warrants further investigation.

Several potential limitations of the present study need to be acknowledged. First, as mentioned above, the fact that we do not have access to the individual level data from the included studies raises a possibility that the association estimates used in our study may not be fully adjusted for. Reproductive factors and smoking are known risk factors for endometrial cancer [43, 47, 48]. However, in some of the studies included in our metaanalyses, not all of these known factors were sufficiently adjusted for [13-15, 19, 29, 30]. Second, differences in the assessment of intake of fish/n-3 PUFA across studies could be an important source of heterogeneity. In seven of the 16 included studies, trained interviewers collected the dietary intake data $[13,20,22,25,29-31]$, and in the remaining nine studies, a self-administered questionnaire was used to collect dietary information [14-19, 21, 24, 49]. It is known that the collection method of questionnaire may cause inaccuracy and measurement error. Recall bias may also be an issue in the 11 included case-control studies. Additional well-designed studies are warranted to validate our findings. Third, the evidence synthesized from our analyses was from observational studies, which are known to confer biases due to the observational nature. The causal relationship could not be inferred from such studies. Fourth, we noticed considerable heterogeneities across studies in our pooled analyses. We conducted multiple subgroup analyses with the hope of detecting potential factors for such heterogeneities; however, in many strata the heterogeneity remains relatively high. All these limitations need to be considered when interpreting our findings. Fifth, our analyses comparing the highest category versus the lowest category of dietary intake and dose-response analyses did not always suggest the same pattern of findings, especially for analyses of fish intake. For example, the detected significant associations for every one additional serving/week of fish intake in subgroups of studies conducted in Asia or Europe or according to smoking adjustment were not suggested in the analyses comparing the highest versus lowest category of fish consumption. Whether such inconsistences were due to dose-response analysis's better capturing of exposure pattern or not warrants further exploration.

In conclusion, after summarizing all available evidence from epidemiological studies, intake of fish is significantly associated with reduced endometrial cancer risk in studies adjusted for smoking and those conducted in Europe. DHA tends to be inversely associated with risk of endometrial cancer in a nonlinear relationship. Further well-designed studies are warranted to better characterize the relationship between fish, n-3 PUFA and endometrial cancer development.

\section{MATERIALS AND METHODS}

\section{Data sources and search strategies}

We conducted a literature search of PubMed (MEDLINE) and Embase through March 2017 to identify eligible epidemiological studies. The following search keywords were used: (endometrium OR endometrial) AND (malignancies OR malignancy OR neoplasm OR neoplasms OR cancer OR cancers OR adenoma OR adenomas OR carcinoma OR carcinomas) AND (fatty

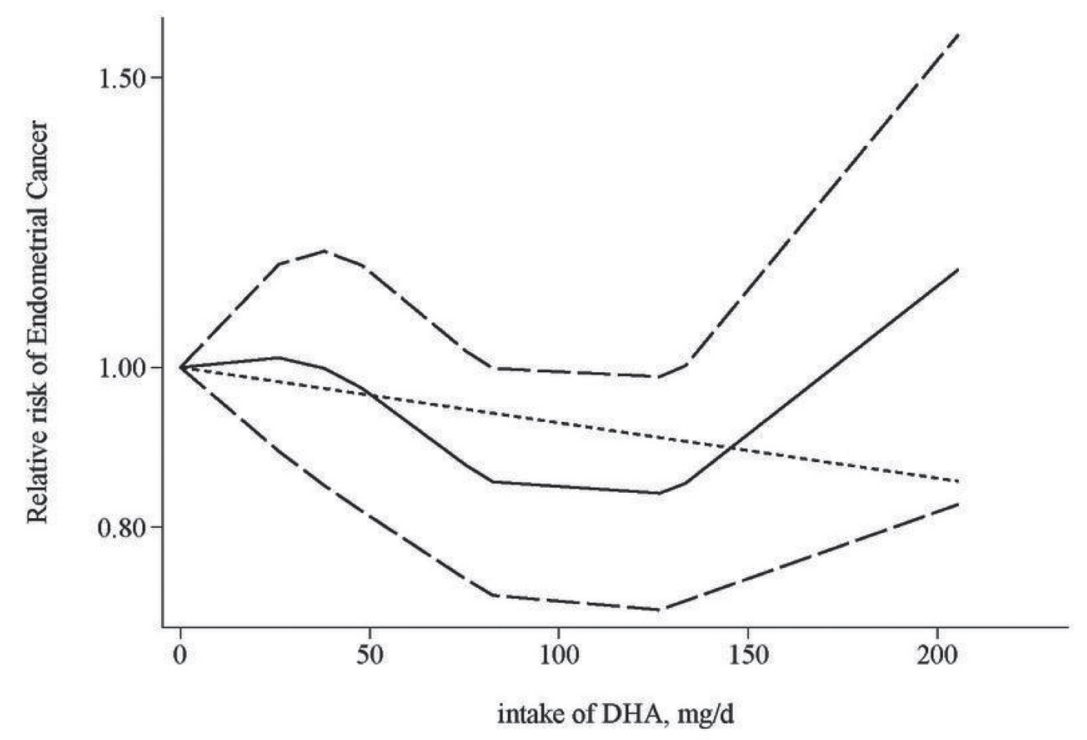

Figure 3: Dose-response relationship for the association between intake of DHA and endometrial cancer risk. The solid line represents the estimated relationship. The dashed line represents the $95 \%$ confidence interval of the estimated relationship. 
acid OR docosahexaenoic acid OR eicosapentaenoic acid OR docosapentaenoic acid OR alpha-linolenic acid OR polyunsaturated fatty acid OR omega-3 fatty acid OR n-3 fatty acid OR fish OR fish oil OR seafood). There was no language restriction. We also reviewed the reference lists of the identified articles and related review and metaanalysis articles to identify additional potential studies.

\section{Study selection}

Studies were eligible if they $(i)$ were prospective studies or case-control studies, (ii) evaluated the association between fish intake or n-3 PUFA intake (EPA or DHA) and endometrial cancer risk, and (iii) presented odds ratio (OR), relative risk ( $\mathrm{RR})$, or hazard ratio (HR) estimates with $95 \%$ confidence intervals $(\mathrm{CI})$ or necessary data for calculation. Studies were included regardless of sample size. If multiple publications regarding the same study were identified, we retained the study with the largest number of cases in our analyses.

\section{Data extraction and quality assessment}

A pair of investigators independently conducted the title/abstract screening, full-text screening, data extraction, and quality assessment. Disagreements were resolved by joint reevaluation, with inputs from other investigators. The data that were extracted from each study included the following: author's name, publication year, study location, study design, and characteristics of the study sample (sample size, age, categories of fish/n-3 PUFA intake, and association estimates). If there were multiple estimates of the association, we used the estimate with adjustments for the most appropriate covariates.

To assess the quality of included studies, we used the Newcastle-Ottawa Quality Assessment Scale [50]. This scale evaluates various aspects including the population and sampling methods, exposure and outcome collections, and statistical matching/adjustments of the data etc. The quality scores were determined for each study, with a maximum possible score of 9 . Studies with scores $\geq 7$ were classified as high-quality studies; studies with scores $<7$ were classified as low-quality studies.

\section{Statistical methods}

We synthesized association estimates for intake of fish, EPA, and DHA. For each one, pooled estimates comparing the highest category and the lowest category of dietary intake were synthesized. Due to the rarity of endometrial cancer in the general population, ORs and HRs were deemed equivalent to RRs and RRs were used to represent association estimates. The $I^{2}$ were used to assess heterogeneity across studies, with a $I^{2}>50 \%$ suggesting high heterogeneity $[51,52]$. The randomeffects model was used to pool the log-transformed RR when there was high heterogeneity [53], and the fixedeffects model was used when there was no considerable heterogeneity [54]. We also performed subgroup analyses to examine the robustness of the findings within strata defined by study design, location, control type, number of cases $(\geq 500$ or $<500)$, publication year (2010- or before 2010), and adjustments of energy intake, reproductive factors, and smoking. With regard to publication bias, Egger's test [55] and Begg's test [56] were performed. A $p$ value of less than 0.05 was considered to indicate significant publication bias.

For the dose-response analyses, we explored both non-linear and linear relationships between intake of fish/n-3 PUFA (EPA or DHA) and endometrial cancer risk [57]. The method proposed by Greenland et al. [57] was used to determine study-specific slopes (linear trends) and 95\% CIs from the natural logs of the RRs and CIs across categories of intake of fish or n-3 PUFA (EPA or DHA). For this analysis, the number of cases, person-years of non-cases, RRs, and 95\% CIs for at least three exposure categories were needed. We assessed the relationship at increments of 1 serving/week for fish consumption and $1 \mathrm{mg} / \mathrm{d}$ for n-3 PUFA exposures. When fish intake was reported in unit of $\mathrm{g} / \mathrm{d}$, it was converted to serving/week by assuming 1 serving $=100 \mathrm{~g}$. We set the midpoint of each reported category by averaging the lower and upper bounds. In studies where the highest category of intake of fish or n-3 PUFA did not have an upper bound, we assumed a same width of the open ended interval with that of its adjacent interval $[58,59]$. We also examined potential nonlinear dose-response relationships using fractional polynomial models with restricted cubic splines and four knots at fixed percentiles $(5 \%, 35 \%, 65 \%$, and $95 \%$ ) of the distribution [39]. A likelihood ratio test was performed to determine whether a nonlinear or linear relationship was more appropriate. All statistical analyses were performed using Stata 12.1 software (StataCorp, College Station, TX, USA).

\section{CONFLICTS OF INTEREST}

The authors declare that they have no conflicts of interest.

\section{REFERENCES}

1. Society AC. Global Cancer Facts \& Figures. 3rd ed. Atlanta: American Cancer Society; 2015.

2. Siegel RL, Miller KD, Jemal A. Cancer Statistics, 2017. CA Cancer J Clin. 2017; 67:7-30.

3. Geelen A, Schouten JM, Kamphuis C, Stam BE, Burema J, Renkema JM, Bakker EJ, van't Veer P, Kampman E. Fish consumption, n-3 fatty acids, and colorectal cancer: a metaanalysis of prospective cohort studies. Am J Epidemiol. 2007; 166:1116-25. 
4. Wu S, Feng B, Li K, Zhu X, Liang S, Liu X, Han S, Wang B, Wu K, Miao D, Liang J, Fan D. Fish consumption and colorectal cancer risk in humans: a systematic review and meta-analysis. Am J Med. 2012; 125:551-9.e5.

5. Salehi M, Moradi-Lakeh M, Salehi MH, Nojomi M, Kolahdooz F. Meat, fish, and esophageal cancer risk: a systematic review and dose-response meta-analysis. Nutr Rev. 2013; 71:257-67.

6. Zheng JS, Hu XJ, Zhao YM, Yang J, Li D. Intake of fish and marine $n-3$ polyunsaturated fatty acids and risk of breast cancer: meta-analysis of data from 21 independent prospective cohort studies. BMJ. 2013; 346:f3706.

7. Song J, Su H, Wang BL, Zhou YY, Guo LL. Fish consumption and lung cancer risk: systematic review and meta-analysis. Nutr Cancer. 2014; 66:539-49.

8. Yu XF, Zou J, Dong J. Fish consumption and risk of gastrointestinal cancers: a meta-analysis of cohort studies. World J Gastroenterol. 2014; 20:15398-412.

9. Gao M, Sun K, Guo M, Gao H, Liu K, Yang C, Li S, Liu N. Fish consumption and n-3 polyunsaturated fatty acids, and risk of hepatocellular carcinoma: systematic review and meta-analysis. Cancer Causes Control. 2015; 26:367-76.

10. Huang RX, Duan YY, Hu JA. Fish intake and risk of liver cancer: a meta-analysis. PLoS One. 2015; 10:e0096102.

11. Wang YZ, Wu QJ, Zhu J, Wu L. Fish consumption and risk of myeloma: a meta-analysis of epidemiological studies. Cancer Causes Control. 2015; 26:1307-14.

12. Lian W, Wang R, Xing B, Yao Y. Fish intake and the risk of brain tumor: a meta-analysis with systematic review. Nutr J. $2017 ; 16: 1$.

13. Fernandez E, Chatenoud L, La Vecchia C, Negri E, Franceschi S. Fish consumption and cancer risk. Am J Clin Nutr. 1999; 70:85-90.

14. Takayama S, Monma Y, Tsubota-Utsugi M, Nagase S, Tsubono Y, Numata T, Toyoshima M, Utsunomiya H, Sugawara J, Yaegashi N. Food intake and the risk of endometrial endometrioid adenocarcinoma in Japanese women. Nutr Cancer. 2013; 65:954-60.

15. Terry P, Wolk A, Vainio H, Weiderpass E. Fatty fish consumption lowers the risk of endometrial cancer: a nationwide case-control study in Sweden. Cancer Epidemiol Biomarkers Prev. 2002; 11:143-45.

16. Arem H, Neuhouser ML, Irwin ML, Cartmel B, Lu L, Risch H, Mayne ST, Yu H. Omega-3 and omega-6 fatty acid intakes and endometrial cancer risk in a population-based case-control study. Eur J Nutr. 2013; 52:1251-60.

17. Brasky TM, Rodabough RJ, Liu J, Kurta ML, Wise LA, Orchard TS, Cohn DE, Belury MA, White E, Manson JE, Neuhouser ML. Long-chain $\omega-3$ fatty acid intake and endometrial cancer risk in the Women's Health Initiative. Am J Clin Nutr. 2015; 101:824-34.

18. Brasky TM, Sponholtz TR, Palmer JR, Rosenberg L, RuizNarváez EA, Wise LA. Associations of dietary long-chain omega-3 polyunsaturated fatty acids and fish consumption with endometrial cancer risk in the black women's health study. Am J Epidemiol. 2016; 183:199-209.
19. Daniel CR, Cross AJ, Graubard BI, Hollenbeck AR, Park Y, Sinha R. Prospective investigation of poultry and fish intake in relation to cancer risk. Cancer Prev Res (Phila). 2011; 4:1903-11.

20. Filomeno M, Bosetti C, Bidoli E, Levi F, Serraino D, Montella M, La Vecchia C, Tavani A. Mediterranean diet and risk of endometrial cancer: a pooled analysis of three Italian case-control studies. Br J Cancer. 2015; 112:1816-21.

21. Hirose K, Tajima K, Hamajima N, Takezaki T, Inoue M, Kuroishi T, Kuzuya K, Nakamura S, Tokudome S. Subsite (cervix/endometrium)-specific risk and protective factors in uterus cancer. Jpn J Cancer Res. 1996; 87:1001-09.

22. Jain MG, Rohan TE, Howe GR, Miller AB. A cohort study of nutritional factors and endometrial cancer. Eur J Epidemiol. 2000; 16:899-905.

23. Cui X, Rosner B, Willett WC, Hankinson SE. Dietary fat, fiber, and carbohydrate intake in relation to risk of endometrial cancer. Cancer Epidemiol Biomarkers Prev. 2011; 20:978-89.

24. Brasky TM, Neuhouser ML, Cohn DE, White E. Associations of long-chain $\omega-3$ fatty acids and fish intake with endometrial cancer risk in the VITamins And Lifestyle cohort. Am J Clin Nutr. 2014; 99:599-608.

25. Xu WH, Dai Q, Xiang YB, Zhao GM, Zheng W, Gao YT, Ruan ZX, Cheng JR, Shu XO. Animal food intake and cooking methods in relation to endometrial cancer risk in Shanghai. Br J Cancer. 2006; 95:1586-92.

26. Bandera EV, Kushi LH, Moore DF, Gifkins DM, McCullough ML. Consumption of animal foods and endometrial cancer risk: a systematic literature review and meta-analysis. Cancer Causes Control. 2007; 18:967-88.

27. Arem H, Gunter MJ, Cross AJ, Hollenbeck AR, Sinha R. A prospective investigation of fish, meat and cooking-related carcinogens with endometrial cancer incidence. Br J Cancer. 2013; 109:756-60.

28. van Lonkhuijzen L, Kirsh VA, Kreiger N, Rohan TE. Endometrial cancer and meat consumption: a case-cohort study. Eur J Cancer Prev. 2011; 20:334-9.

29. Shu XO, Zheng W, Potischman N, Brinton LA, Hatch MC, Gao YT, Fraumeni JF Jr. A population-based casecontrol study of dietary factors and endometrial cancer in Shanghai, People's Republic of China. Am J Epidemiol. 1993; 137:155-65.

30. Goodman MT, Hankin JH, Wilkens LR, Lyu LC, McDuffie K, Liu LQ, Kolonel LN. Diet, body size, physical activity, and the risk of endometrial cancer. Cancer Res. 1997; 57:5077-85.

31. McCann SE, Freudenheim JL, Marshall JR, Brasure JR, Swanson MK, Graham S. Diet in the epidemiology of endometrial cancer in western New York (United States). Cancer Causes Control. 2000; 11:965-74.

32. Malekshahi Moghadam A, Saedisomeolia A, Djalali M, Djazayery A, Pooya S, Sojoudi F. Efficacy of omega-3 fatty acid supplementation on serum levels of tumour necrosis 
factor-alpha, C-reactive protein and interleukin-2 in type 2 diabetes mellitus patients. Singapore Med J. 2012; 53:615-19.

33. Ebrahimi M, Ghayour-Mobarhan M, Rezaiean S, Hoseini M, Parizade SM, Farhoudi F, Hosseininezhad SJ, Tavallaei S, Vejdani A, Azimi-Nezhad M, Shakeri MT, Rad MA, Mobarra N, et al. Omega-3 fatty acid supplements improve the cardiovascular risk profile of subjects with metabolic syndrome, including markers of inflammation and autoimmunity. Acta Cardiol. 2009; 64:321-27.

34. Micallef MA, Munro IA, Garg ML. An inverse relationship between plasma n-3 fatty acids and C-reactive protein in healthy individuals. Eur J Clin Nutr. 2009; 63:1154-56.

35. Kantor ED, Lampe JW, Vaughan TL, Peters U, Rehm CD, White E. Association between use of specialty dietary supplements and C-reactive protein concentrations. Am J Epidemiol. 2012; 176:1002-13.

36. Wang T, Rohan TE, Gunter MJ, Xue X, Wactawski-Wende J, Rajpathak SN, Cushman M, Strickler HD, Kaplan RC, Wassertheil-Smoller S, Scherer PE, Ho GY. A prospective study of inflammation markers and endometrial cancer risk in postmenopausal hormone nonusers. Cancer Epidemiol Biomarkers Prev. 2011; 20:971-77.

37. Dossus L, Rinaldi S, Becker S, Lukanova A, Tjonneland A, Olsen A, Stegger J, Overvad K, Chabbert-Buffet N, Jimenez-Corona A, Clavel-Chapelon F, Rohrmann S, Teucher B, et al. Obesity, inflammatory markers, and endometrial cancer risk: a prospective case-control study. Endocr Relat Cancer. 2010; 17:1007-19.

38. Dossus L, Becker S, Rinaldi S, Lukanova A, Tjønneland A, Olsen A, Overvad K, Chabbert-Buffet N, BoutronRuault MC, Clavel-Chapelon F, Teucher B, Chang-Claude $\mathrm{J}$, Pischon T, et al. Tumor necrosis factor (TNF)- $\alpha$, soluble TNF receptors and endometrial cancer risk: the EPIC study. Int J Cancer. 2011; 129:2032-37.

39. Wallace AE, Gibson DA, Saunders PT, Jabbour HN. Inflammatory events in endometrial adenocarcinoma. J Endocrinol. 2010; 206:141-57.

40. Chapkin RS, Kim W, Lupton JR, McMurray DN. Dietary docosahexaenoic and eicosapentaenoic acid: emerging mediators of inflammation. Prostaglandins Leukot Essent Fatty Acids. 2009; 81:187-91.

41. Ebert AD, Bartley J, David M. Aromatase inhibitors and cyclooxygenase-2 (COX-2) inhibitors in endometriosis: new questions - old answers? Eur J Obstet Gynecol Reprod Biol. 2005; 122:144-50.

42. Allen NE, Key TJ, Dossus L, Rinaldi S, Cust A, Lukanova A, Peeters PH, Onland-Moret NC, Lahmann PH, Berrino F, Panico S, Larrañaga N, Pera G, et al. Endogenous sex hormones and endometrial cancer risk in women in the European Prospective Investigation into Cancer and Nutrition (EPIC). Endocr Relat Cancer. 2008; 15:485-97.

43. Wu QJ, Li YY, Tu C, Zhu J, Qian KQ, Feng TB, Li C, Wu L, Ma XX. Parity and endometrial cancer risk: a meta-analysis of epidemiological studies. Sci Rep. 2015; 5:14243.

44. Calder PC, Grimble RF. Polyunsaturated fatty acids, inflammation and immunity. Eur J Clin Nutr. 2002 (Suppl 3); 56:S14-19.
45. Popp-Snijders C, Schouten JA, Heine RJ, van der Meer J, van der Veen EA. Dietary supplementation of omega-3 polyunsaturated fatty acids improves insulin sensitivity in noninsulin-dependent diabetes. Diabetes Res. 1987; 4:141-47.

46. Mori Y, Murakawa Y, Katoh S, Hata S, Yokoyama J, Tajima N, Ikeda Y, Nobukata H, Ishikawa T, Shibutani Y. Influence of highly purified eicosapentaenoic acid ethyl ester on insulin resistance in the Otsuka Long-Evans Tokushima Fatty rat, a model of spontaneous non-insulin-dependent diabetes mellitus. Metabolism. 1997; 46:1458-64.

47. Gong TT, Wang YL, Ma XX. Age at menarche and endometrial cancer risk: a dose-response meta-analysis of prospective studies. Sci Rep. 2015; 5:14051.

48. Zhou B, Yang L, Sun Q, Cong R, Gu H, Tang N, Zhu H, Wang B. Cigarette smoking and the risk of endometrial cancer: a meta-analysis. Am J Med. 2008; 121:501-508.e3.

49. van Lonkhuijzen L, Kirsh VA, Kreiger N, Rohan TE. Endometrial cancer and meat consumption: a case-cohort study. Eur J Cancer Prev. 2011; 20:334-39.

50. Wells GA, Shea B, O'Connell D, Peterson J, Welch V, Losos M, Tugwell P. The Newcastle-Ottawa Scale (NOS) for assessing the quality of nonrandomised studies in meta-analyses. http://www.ohri.ca/programs/clinical_ epidemiology/oxford.asp.

51. Higgins JP, Thompson SG, Deeks JJ, Altman DG. Measuring inconsistency in meta-analyses. BMJ. 2003; 327:557-60.

52. Kuang D, Chen W, Song YZ, Yu YY, Zhang DY, Wu L, Tang J. Association between the HSPA1B $\pm 1267 \mathrm{~A} / \mathrm{G}$ polymorphism and cancer risk: a meta-analysis of 14 casecontrol studies. Asian Pac J Cancer Prev. 2014; 15:6855-61.

53. DerSimonian R, Laird N. Meta-analysis in clinical trials. Control Clin Trials. 1986; 7:177-88.

54. Higgins JP, Thompson SG. Quantifying heterogeneity in a meta-analysis. Stat Med. 2002; 21:1539-58.

55. Egger M, Davey Smith G, Schneider M, Minder C. Bias in meta-analysis detected by a simple, graphical test. BMJ. 1997; 315:629-34.

56. Begg CB, Mazumdar M. Operating characteristics of a rank correlation test for publication bias. Biometrics. 1994; 50:1088-101.

57. Greenland S, Longnecker MP. Methods for trend estimation from summarized dose-response data, with applications to meta-analysis. Am J Epidemiol. 1992; 135:1301-09.

58. Wang Q, Wang Y, Ji Z, Chen X, Pan Y, Gao G, Gu H, Yang Y, Choi BC, Yan Y. Risk factors for multiple myeloma: a hospital-based case-control study in Northwest China. Cancer Epidemiol. 2012; 36:439-44.

59. Fritschi L, Ambrosini GL, Kliewer EV, Johnson KC, and Canadian Cancer Registries Epidemiologic Research Group. Dietary fish intake and risk of leukaemia, multiple myeloma, and non-Hodgkin lymphoma. Cancer Epidemiol Biomarkers Prev. 2004; 13:532-37. 